\title{
Easybreath Decathlon Mask: An Efficient Personal Protective Equipment (PPE) against COVID-19 in Africa
}

\author{
Rachid Ait Addi ${ }^{1,2^{*}}$, Abdelhafid Benksim ${ }^{3}$, Mohamed Cherkaoui ${ }^{1}$
}

${ }^{1}$ Laboratory of Human Ecology, Semlalia School of Sciences, Cadi Ayyad University, Marrakesh, Morocco

${ }^{2} \mathrm{Al}$ Amal Dental Clinic, Marrakesh, Morocco

${ }^{3}$ High Institute of Nursing, Marrakesh, Morocco

\section{Correspondence:}

Rachid Ait Addi

Address: Laboratory of Human Ecology, Semlalia School of Sciences, Cadi Ayyad University, Marrakesh, Morocco

Email: dr.rachid.aitaddi@gmail.com

Received: 04.04.2020,

Accepted: 04.04 .2020

https://doi.org/10.5799/jcei/7894
Coronavirus disease 2019 caused by a novel coronavirus was first identified in Wuhan, China and rapidly spread across the world $[1,2]$.

Health workers found themselves at the front lines of the pandemic with high risk of contamination. Indeed, additional precautions are required by health care workers to protect themselves and prevent transmission in the healthcare setting. Health care workers must adopt precautions as using of Personal Protective Equipment (PPE), by proper selection of PPE and knowing how to put, remove and dispose of it [3].

PPE comprises gloves, medical masks, goggles or a face shield, and gowns, as well as for specific procedures, respirator masks (i.e. N95 or FFP2 standard or equivalent) and aprons [3].

With the COVID-19 outbreak, a penury of PPE was seen all over the word and especially in FFP2 masks, which is due to high demand and the closure of almost all factories especially in China [4].

Faced with this shortage, health workers had to find ways to protect themselves while waiting for the arrival of standard means.
The idea started in some European hospitals and then medical offices whom begin to use Easybreath Decathlon mask; which is designed to submarine diving and characterized by its high sealing; like a mean of personal protective equipment to substitute at the same time to FFP2 masks and face shield (Figures 1-3).

The major advantages of this mask is that it covers the entire face, also it is easily cleaned, disinfected and serializable. Also, because of its low cost, durability (not disposable), it may be an ultimate alternative of PPE in Africa due to lack of financial resources. It could be fundamental and may save many health workers to distribute Easybreath decathlon mask to all African hospitals whom are fighting COVID-19 infection.

\section{ACKNOWLEDGEMENTS}

The authors want to acknowledge the Editorial office of the journal and all the anonymous reviewers. We also thank the Moroccan govenment for all its efforts, and all health care workers whom are on the front lines of the pandemic. 


\section{Easybreath Decathlon mask against COVID-19 in Africa}

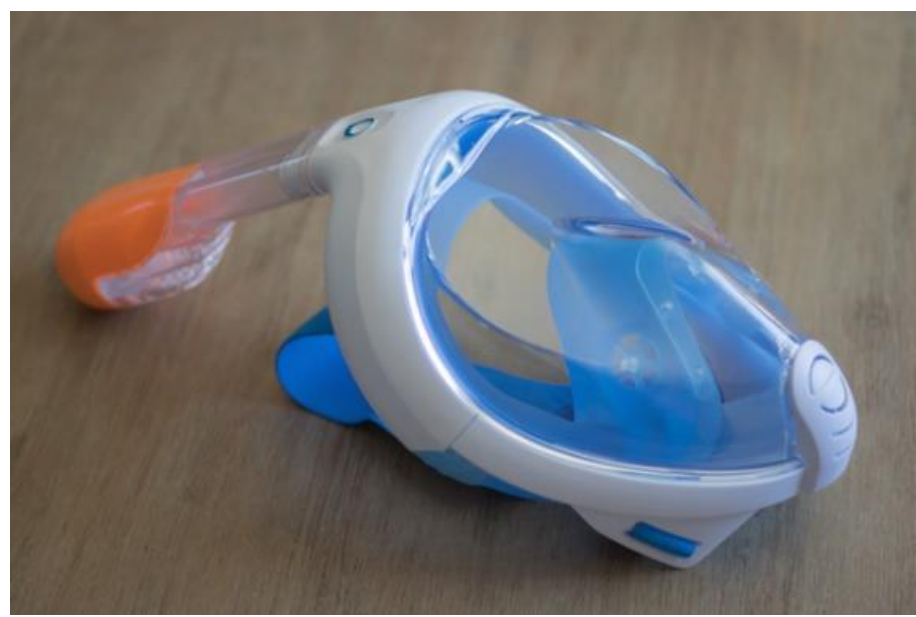

Figure 1. Easybreath Decathlon mask [5]

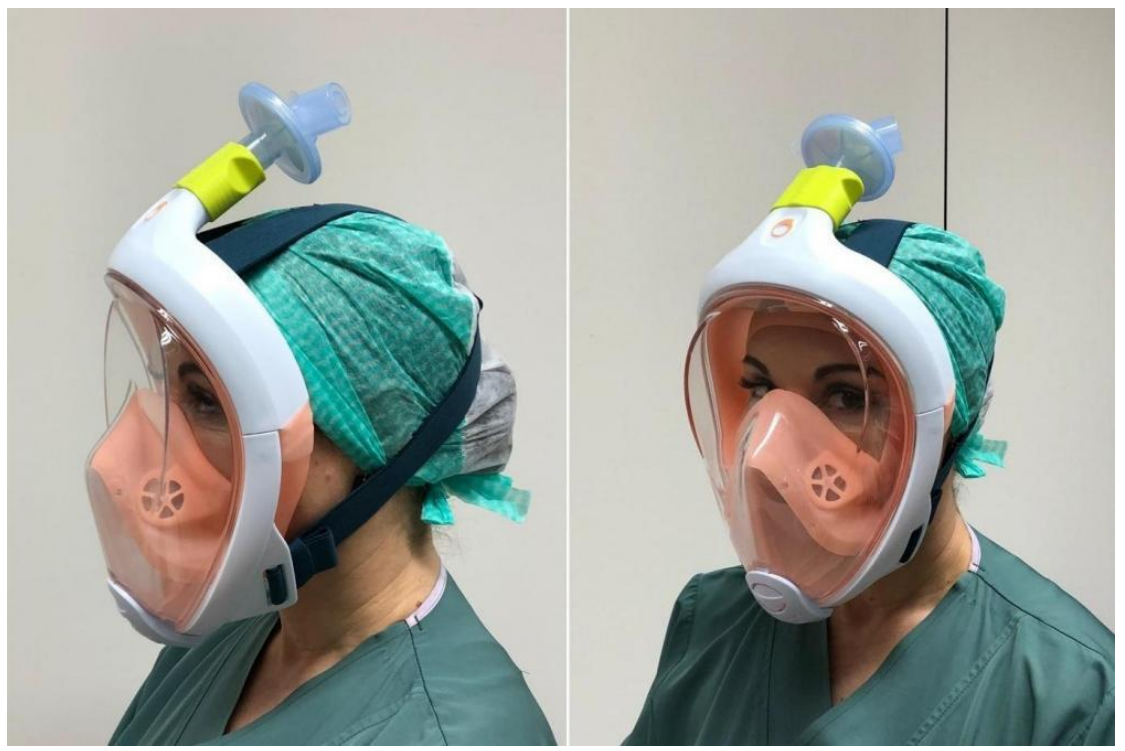

Figure 2. Easybreath Decathlon mask with a filter adapted to the top of the mask (Dr. Benedicte Geniets, anesthesiologist in Antwerp, Belgium) [6]

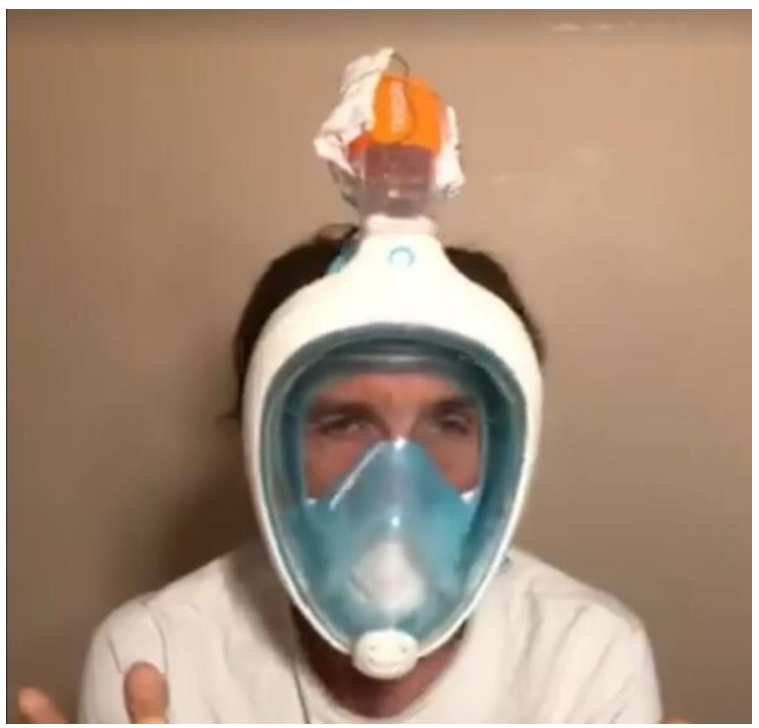

Figure 3. Easybreath Decathlon mask with use of un mask FFP2 as a filter in the top of the mask (Dr Paul Amas; a frensh dentist in a video explaining the method of use) [7] 


\section{Author's Contributions}

Literature search, manuscript preparation and editing were done by R.A.A, manuscript review was carried out by A.B. The supervision was done by M.C and the whole manuscript was read and approved by all the author.

Declaration of interest: The authors report no conflicts of interest.

Financial Disclosure: No financial support was received.

\section{REFERENCES}

1. Ait Addi R, Benksim A, Amine M, Cherkaoui M. COVID-19 Outbreak and Perspective in Morocco. Electron J Gen Med. 2020;17(4):em204. doi: 10.29333/ejgm/7857.

2. Ait Addi R, Benksim A, Amine M, Cherkaoui M. Asymptomatic COVID-19 Infection Management: The Key to Stop COVID-19. J Clin Exp Invest. 2020;11(3):em00737. doi: 10.5799/jcei/7866.

3. World Health Organization. Rational use of personal protective equipment for coronavirus disease (COVID19). WHO/2019-nCoV/IPC PPE_use/2020.2
4. Mahase E. Novel coronavirus: Australian GPs raise concerns about shortage of face masks BMJ 2020;368:m477 doi: 10.1136/bmj.m477.

5. SUBEA Easybreath surface snorkeling mask printed oyster turquoise. Available at: https://www.decathlon. co.uk/easybreath-mask-oyster-print-id_8514879.html

6. Colart L. Le masque de plongée Décathlon transformé en masque de protection par la VUB. Le Soir .be. 2020. Available at: https://www.lesoir.be/290967/article/202003-30/le-masque-de-plongee-decathlon-transforme-enmasque-de-protection-par-la-vub

7. Cirone C. "C'est le seul moyen de protéger tous les soignants": un dentiste marseillais appelle à donner un masque de plongée pour les protéger du Covid-19. Nicematin. 2020. Available at: https://www.nicematin.com/ sante/cest-le-seul-moyen-de-proteger-tous-lessoignants-un-dentiste-marseillais-appelle-a-donnerun-masque-de-plongee-pour-les-proteger-du-covid$19-486625$ 